\title{
WISSENSCHAFT UND SITTLICHKEIT
}

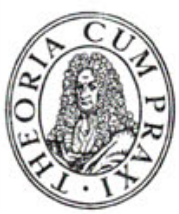

Akademie-Verlag

Berlin 1976

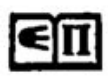

Verlag ${ }_{\text {p PROGRESS }}$ “

Moskau 1976 
Russischer Originaltitel:

НАУКА И НРАВСТВЕННОСТЬ

Издательство политической литературы, Москва 1971

Ins Deutsche übersetzt durch L. STEINMETZ

(c) der deutschen Übersetzung by Progress, Moskau, 1976 Der Vertrieb dieses Exemplares ist nur in der DDR gestattet.

Erschienen im Akademie-Verlag, DDR, 108 Berlin, Leipziger Str. 3-4

Lizenznummer: 202 . 100/327/76

Bestellnummer: 7530850 (6361) LSV. 0305

Printed in USSR

Preis: $18,-\ldots \mathrm{M}$ 